\title{
Research
}

Rachael Frost, Kate Walters, Su Aw, Greta Brunskill, Jane Wilcock, Louise Robinson, Martin Knapp, Karen Harrison Dening, Louise Allan, Jill Manthorpe and Greta Rait; on behalf of the PriDem Study project team

\section{Effectiveness of different post-diagnostic dementia care models delivered by primary care:}

\author{
a systematic review
}

\begin{abstract}
\section{Background}

Global policy recommendations suggest a taskshifted model of post-diagnostic dementia care, moving towards primary and community-based care. It is unclear how this may best be delivered.

Aim

To assess the effectiveness and costeffectiveness of primary care-based models of post-diagnostic dementia care.
\end{abstract}

\section{Design and setting}

A systematic review of trials and economic evaluations of post-diagnostic dementia care interventions where primary care was substantially involved in care plan decision making.

\section{Method}

Searches were undertaken of MEDLINE, PsychINFO, EMBASE, Web of Science, and CINAHL (from inception to March 2019). Two authors independently critically appraised studies and inductively classified interventions into types of care models. Random effects meta-analysis or narrative synthesis was conducted for each model where appropriate.

\section{Results}

From 4506 unique references and 357 full texts 23 papers were included from 10 trials of nine interventions, delivered in four countries. Four types of care models were identified. Primary care provider (PCP)-led care $(n=1)$ led to better caregiver mental health and reduced hospital and memory clinic costs compared with memory clinics. PCP-led care with specialist consulting support $(n=2)$ did not have additional effects on clinical outcomes or costs over usual primary care. PCP-case management partnership models $(n=6)$ offered the most promise, with impact on neuropsychiatric symptoms, caregiver burden, distress and mastery, and healthcare costs. Integrated primary care memory clinics $(n=1)$ had limited evidence for improved quality of life and costeffectiveness compared with memory clinics.

\section{Conclusion}

Partnership models may impact on some clinical outcomes and healthcare costs. More rigorous evaluation of promising primary careled care models is needed.

\section{Keywords}

case management; dementia; models of care primary care; systematic review.

\section{INTRODUCTION}

Approximately 43.8 million people globally were living with dementia in 2016.' This figure is projected to almost double every 20 years, with the largest increase in low- and middle-income countries. ${ }^{2}$ Dementia is a syndrome with a range of cognitive, psychological, and behavioural symptoms, which progressively impair activities of daily living. ${ }^{3}$ Intensive health and social care support is often required. Globally, dementia is estimated to cost US $\$ 818$ billion (€628 billion), 20\% of which relates to direct medical care and $40 \%$ each to social care and informal care. ${ }^{2}$ Caregivers (unpaid family or other supports, also called carers) contribute a large amount of support but can experience substantial caregiving burden. ${ }^{4}$

With increasing prevalence and demand on secondary care services, the World Alzheimer report $2016^{5}$ recommended a global shift towards approaches where post-diagnostic dementia services are based in primary care. Primary care is defined as '... first-contact, accessible, continued, comprehensive and coordinated care'. Post-diagnostic dementia support includes initial treatment lsuch as

R Frost, PhD, research fellow; K Walters, PhD, clinical professor of primary care and epidemiology; J Wilcock, MA(Hons), MSc, senior research fellow: G Rait, MD, clinical professor of primary care and health services research, Department of Primary Care and Population Health, University College London, London, UK. S Aw, MSc, PhD student, Saw Swee Hock School of Public Health, National University of Singapore, Singapore. G Brunskill DClinPsy, research associate; L Robinson, MD, professor of primary care and ageing, Institute for Health and Society, University of Newcastle, UK M Knapp. PhD, professor in health and care policy, Care Policy and Evaluation Centre, London School of Economics and Political Science, London, UK K Harrison Dening. $\mathrm{PhD}$, head of research and publications, Dementia UK, London, UK. L Allan, $\mathrm{PhD}$, professor of geriatric medicine, College of caregiver wellbeing and support, and a post-diagnostic support package), ongoing and continuing care (such as comorbidities management, and behavioural and psychological symptom management), and end-of-life care. ${ }^{5}$ The authors defined primary care-led dementia care as that in which care plan decision making was either led by or substantially involved a member of the primary care team

Little is known about the optimal way to deliver primary care post-diagnostic dementia care, with great variation within and between countries in service content, quality, and providers. Therefore, it is of interest to compare effects between primary and secondary care provision, and between different primary care models. Previous reviews have studied case management approaches, ${ }^{7}$ strategies used to deliver different models of primary care dementia care without a focus on effectiveness, ${ }^{8}$ and a scoping review of dementia interventions relevant to primary care. ${ }^{5}$ These have found limited evidence, particularly regarding the costs of case management and its integration with primary care, the role of specialists, and the potential range of

Medicine and Health, University of Exeter, Exeter, UK. J Manthorpe, MA, professor of social work, NIHR Health and Social Care Workforce Research Unit, Kings College London, London, UK. Address for correspondence

Rachael Frost, Department of Primary Care and Population Health, University College London, Royal Free Campus, Rowland Hill Street, London NW3 2PF, UK

Email: rachael.frostवucl.ac.uk

Submitted: 6 August 2019. Editor's response: 4 September 2019; final acceptance: 17 September 2019.

OBritish Journal of General Practice

This is the full-length article (published online 19 May 2020) of an abridged version published in print. Cite this version as: Br J Gen Pract 2020; DOI https://doi.org/10.3399/bjgp20X710165 


\section{How this fits in}

Global policy recommendations sugges moving to a primary care-led model of post-diagnostic dementia care, but it is unclear how this should best be delivered. This systematic review found primary care provider-led care appears to provide similar outcomes to secondary care memory clinics, while integrated primary care memory clinics may offer cost savings compared to secondary care memory clinics. Adding specialist consulting support into primary care did not appear to improve outcomes over usual primary care. It suggests that a primary care providercase management partnership mode currently offers the most promise. All models need further rigorous evaluation.

outcomes that may be impacted by postdiagnostic support. ${ }^{5}$

In light of this rapidly evolving field and the global policy recommendations, the aim of this review was to assess the effectiveness and cost-effectiveness of models of post-diagnostic dementia care that have substantial involvement from primary care.

\section{METHOD}

A systematic review was undertaken following PRISMA reporting guidelines.?

\section{Inclusion and exclusion criteria}

For inclusion in the review, studies had to report on the following criteria.

Participants. These were people with dementia (post-diagnosis) and their caregivers, either community-dwelling or in care homes (no age limitations).

Interventions. Post-diagnostic dementia care interventions had to substantially involve $\geq 1$ members of a primary care team las defined by the World Health Organization). ${ }^{6}$ For consistency, the term 'primary care provider' (PCP) is used throughout this article.

Comparators. These were usual care or alternative care management models.

Outcomes. These were quality of life, functioning, cognition, depression, behavioural and psychological symptoms of dementia, caregiver outcomes, costs, cost-effectiveness, service use lincluding hospital admissions), care and nursing home admission.
Study type. Studies were randomised and non-randomised controlled trials lincluding cluster trials), and economic evaluations.

Exclusion criteria for studies included:

- interventions that were secondary careled; had no or minimal primary care involvement; were led by care home staff; were focused on diagnosis or prevention; were educational and focused on increasing professional knowledge, confidence, or guideline adherence;

- no comparator;

- studies that were intervention development studies, uncontrolled intervention studies, implementation studies, process evaluations, reviews, surveys, or quality improvement initiatives.

Studies that provided extra information on study methods but not outcomes (such as protocols) were included as supplementary papers, with relevant data extracted to inform quality assessment.

\section{Searches}

Searches were carried out of MEDLINE, PsycINFO, EMBASE, Web of Science, and CINAHL (from inception to March 2019) and studies were deduplicated using Mendeley and Excel functions (see Supplementary Figure S1 for search terms). One author screened titles and abstracts, with 10\% checked independently by a second reviewer. One author screened all full texts and two others shared the second screening, with disagreements resolved through discussion with two other authors. Full texts in another language were screened by a speaker of the language where possible.

One author screened reference lists, performed citation tracking of included papers, and conducted searches of EThOS and trials registers. Protocols, trials register entries, and conference abstracts were followed up through author and citation searches, and author emails, to locate full texts that had not already been found. Reference lists of relevant reviews were also screened. 8,10

\section{Data extraction and quality assessment}

Data were extracted on study characteristics using the template for intervention description and replication (TIDieR) checklist. ${ }^{11}$ Two authors assessed study quality using the Cochrane risk-of-bias tool for randomised controlled trials (RCTs): ${ }^{12}$ the risk of bias in non-randomised studies of interventions (ROBINS-I) tool for non- 


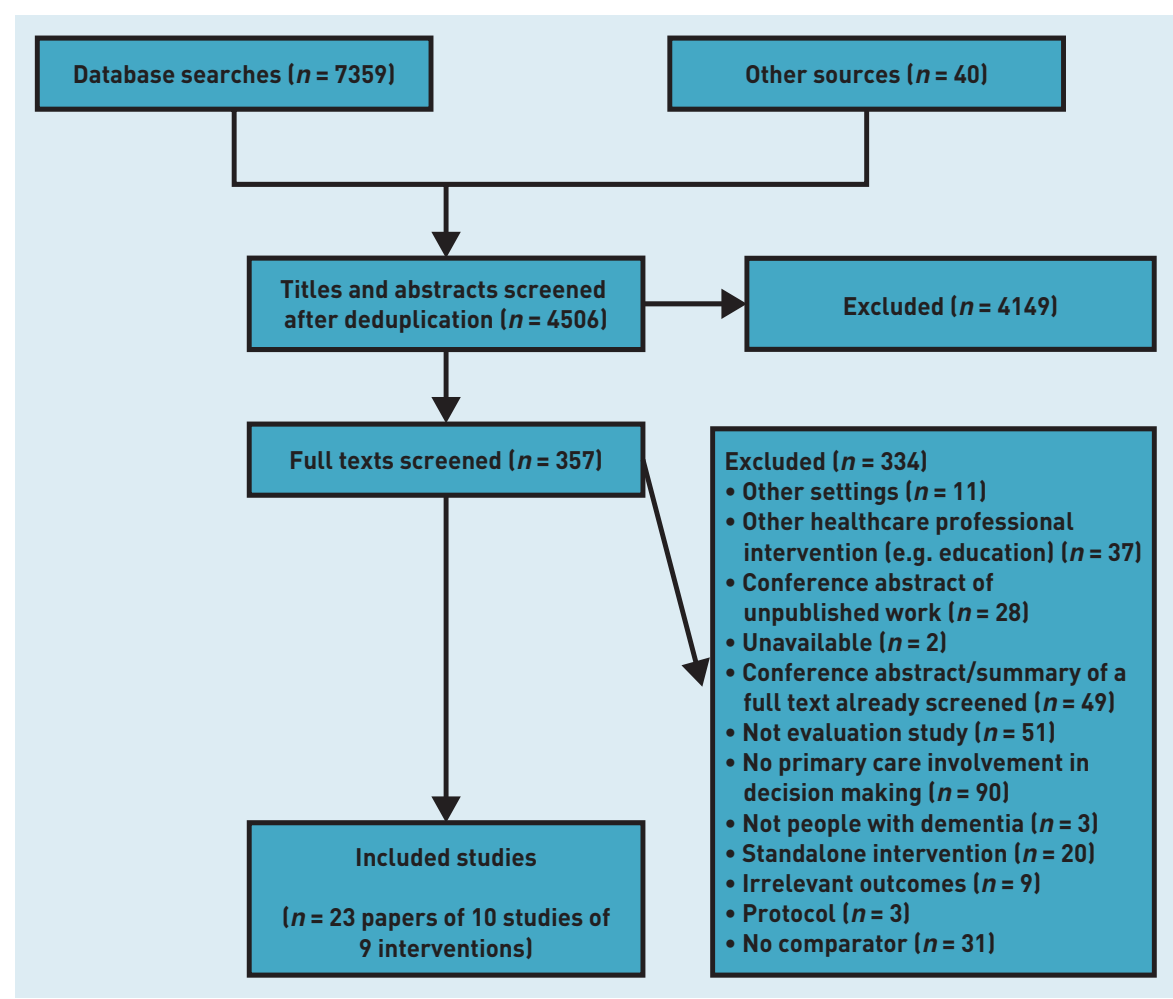

Figure 1. Flow chart of studies included in the review. randomised interventional studies; ${ }^{13}$ and Consensus on Health Economic Criteria (CHEC) checklist for economic evaluations. ${ }^{14}$ Disagreements were resolved through discussion between the same two authors.

\section{Synthesis}

As there is no established taxonomy of primary care-led models of care, two authors inductively grouped study interventions, independently classifying these according to the configuration of healthcare professionals involved. These models were refined with five other team members, then used as the basis for synthesis.

Functioning and quality of life were considered important outcomes. Where multiple studies were available for a model and an outcome with data suitable for aggregation (for example, mean and standard deviation), random-effects metaanalysis was carried out using RevMan (version 5.3), using mean difference, standardised mean difference, or odds ratios. ${ }^{15}$ Non-normally distributed data (for example, medians only reported) were not included in meta-analysis. If outcomes were measured using $\geq 2$ scales, the measure most closely resembling others in the meta-analysis was used to minimise heterogeneity. Heterogeneity was measured using $I^{2}$. For cluster trial outcome data, only effect estimates adjusted for cluster (whether or not they were adjusted for additional variables), meta-analysed using RevMan's generic inverse variance function (standard errors were calculated from reported confidence intervals [Cls]) were included. Where data were reported in a format that could not be included in meta-analysis (such as group $x$ time interaction $P$-value only), the authors were approached for further data $(n=2)$ but a response was not received. Where there were insufficient data for meta-analysis, outcomes were narratively synthesised, grouped by model.

\section{RESULTS}

Out of 4506 deduplicated hits, 357 full texts were screened and 23 papers were included of 10 studies relating to nine services/interventions (Figure 1). See Supplementary Table S1 for characteristics of the included studies. There were five RCTs and four controlled studies. Sample sizes ranged from 31 to 407, with two larger claims-based economic evaluations of 1756 and 3249. Studies were conducted in four countries: the US $(n=5)$, Germany $(n=3)$, the Netherlands $(n=1)$, and Singapore $(n=1)$. Study quality is summarised in Supplementary Figure S2.

\section{Participant characteristics}

Most trials included people diagnosed with dementia, with no severity restrictions. ${ }^{16-22}$ Only three had a new diagnosis or mild-tomoderate dementia as inclusion criteria. ${ }^{23-25}$ Where reported, baseline Mini-Mental State Examination (MMSE) scores ranged from 15.0 to 24.4 (mild-to-moderate dementia). All but one study limited inclusion to those living at home ${ }^{16-18,20-25}$ with a family/ friend caregiver. ${ }^{17,18,20,21,23-25}$ Only one study included those without caregivers, although $79 \%$ of the study sample reported having a caregiver. ${ }^{16}$ In another study, the presence of caregivers was not reported. ${ }^{22}$

\section{Models of care}

Interventions were grouped into four models (Table 1 shows descriptions and associated studies).

\section{PCP-led}

One RCT found that PCP-led care did not lead to significantly different outcomes compared with memory clinics in functioning (Interview for Deterioration in Daily Living Activities in Dementia scale), quality of life (Quality of Life in Alzheimer's Disease [QOL-AD]), behavioural and psychological symptoms of dementia 


\section{Table 1. Description of model classifications and relevant studies in review}

\begin{tabular}{|c|c|c|c|c|}
\hline Model name & Studies & Model description & Comparator & Quality of evidence \\
\hline PCP-led & $\begin{array}{l}n=1 \text { RCT with EE, } \\
\text { the Netherlands }\end{array}$ & $\begin{array}{l}\text { Post-diagnosis care is provided and coordinated by } \\
\text { the PCP. In the single study available (AD-EURO), }{ }^{24} \\
\text { management was based on Dutch general practice } \\
\text { dementia guidelines and provided over } 12 \text { months }\end{array}$ & Memory clinics & $\begin{array}{l}\text { RCT had low risk of bias in five domains, } \\
\text { high risk for participant blinding. EE } \\
\text { met most of the } \mathrm{CHEC} \text { criteria }\end{array}$ \\
\hline $\begin{array}{l}\text { PCP-led with } \\
\text { specialist } \\
\text { consulting } \\
\text { support }\end{array}$ & $\begin{array}{l}n=1 \mathrm{RCT} \text { (three-arm) with } \\
\mathrm{EE}, n=1 \mathrm{CCT} \text {, Germany }\end{array}$ & $\begin{array}{l}\text { The PCP leads post-diagnostic care, with specialist } \\
\text { support for complex or crisis cases, }{ }^{16,23} \text { in the form } \\
\text { of an interdisciplinary dementia support network, }{ }^{16} \\
\text { or specialists (neurologists or psychiatrists). }{ }^{23} \text { One } \\
\text { also recommended a family caregiver support, and } \\
\text { psychoeducational group and optional family caregiver } \\
\text { counselling (after } 12 \text { months in one group }{ }^{23}\end{array}$ & $\begin{array}{l}\text { Usual primary } \\
\text { care }\end{array}$ & $\begin{array}{l}\text { RCT moderate quality. EE met all but } \\
\text { one CHEC criteria. CCT critical risk of } \\
\text { bias due to difference in outcome } \\
\text { follow-up timepoints ( } 11.2 \text { months in } \\
\text { intervention, } 6.6 \text { months in control) }\end{array}$ \\
\hline $\begin{array}{l}\text { PCP-case } \\
\text { management } \\
\text { partnership }\end{array}$ & $\begin{array}{l}n=3 \text { RCTs, } n=1 \text { CCT } \\
n=2 \text { EEs ( } 5 \text { US, } 1 \text { Germany) }\end{array}$ & $\begin{array}{l}\text { Post-diagnostic care is led by a case manager } \\
\text { (usually a nurse), with a structured needs assessment. } \\
\text { A care plan is formed with input from a PCP either on } \\
\text { specific aspects of care (for example, medication or urgent } \\
\text { symptoms), }{ }^{17,18,22,25} \text { or the whole care plan } .^{20} \text { All were } \\
\text { delivered face to face over } 12 \text { months, }{ }^{18,20,25} \text { except one } \\
\text { delivered entirely by phone for } 3 \text { months, }{ }^{17} \text { and one } \\
\text { unclear. }{ }^{19} \text { Contacts varied bi-monthly to tri-monthly, with } \\
\text { contacts usually becoming less frequent over time. } \\
\text { Additional components in some studies included a } \\
\text { telephone caregiver education programme, }{ }^{17} \text { and a } \\
\text { chair-based exercise group (people with dementia) } \\
\text { and support group (caregiver). }{ }^{18} \text { Four services had } \\
\text { specialist input, such as out-of-hours geriatrician } \\
\text { support for the person with dementia and caregiver, }{ }^{22} \\
\text { or interdisciplinary case conferences to support the } \\
\text { case manager }{ }^{20} \text { and(or) PCP }{ }^{18}\end{array}$ & $\begin{array}{l}\text { Usual primary } \\
\text { care }\end{array}$ & $\begin{array}{l}\text { RCTs mixed quality (2-3 domains at } \\
\text { high risk of bias and } 3-5 \text { domains at low } \\
\text { risk). CCT at serious risk of bias. EEs } \\
\text { were mixed quality (meeting less than } \\
\text { two-thirds of the quality criteria) }\end{array}$ \\
\hline $\begin{array}{l}\text { Integrated } \\
\text { models }\end{array}$ & $\begin{array}{l}n=1 \text { CCT (three arm) with } \\
E E, \text { Singapore }\end{array}$ & $\begin{array}{l}\text { Consultations with the primary care physician and } \\
\text { nurse were co-run with a memory clinic geriatrician } \\
\text { and nurse, with fortnightly case conference discussions } \\
\text { to address concerns or challenges in dementia care } \\
\text { and referrals to other allied professionals as necessary, } \\
\text { delivered over } 12 \text { months }{ }^{21}\end{array}$ & $\begin{array}{l}\text { Usual primary care, } \\
\text { usual memory clinic }\end{array}$ & $\begin{array}{l}\text { CCT at serious risk of bias. EE met } \\
\text { most } \mathrm{CHEC} \text { criteria }\end{array}$ \\
\hline
\end{tabular}

$C C T=$ controlled clinical trial. $C H E C=$ Consensus on Health Economic Criteria. $E E=$ economic evaluation. $P C P=$ primary care provider. $R C T=$ randomised controlled trial.

(Neuropsychiatric Inventory [NPI]), or depression care over 6 or 12 months. ${ }^{24}$ There were lower caregiver anxiety (StateTrait Anxiety Inventoryl and depression scores (Centre for Epidemiological Studies Depression scale [CES-D]) at follow-up, but this may be due to dropouts as they were not sustained after a sensitivity analysis imputing missing values. ${ }^{24}$ There were no differences in burden, mastery, and quality of life at 6 or 12 months. ${ }^{24}$

The associated economic evaluation found similar use of health and social care services to memory clinics. There were greater PCP contact costs but lower hospital admission and memory clinic contact costs. ${ }^{26}$ When a societal perspective was taken lincluding informal and formal care, productivity loss, and community and health service use), there were no significant differences in overall costs
€23 059 [€19 639] per patient in the GP group versus €22 035 [€18 766] per patient in the memory clinic group, a difference of €1024 [€873]; 95\% Cl = -€7723 to €5674 [-€6577 to €4832]] or quality-adjusted life year (QALY) gains, although QALYs favoured the PCP-led group.

\section{PCP-led with specialist consulting support}

Compared with usual primary care, one moderate-quality three-arm RCT and one low-quality controlled clinical trial (CCT) found no significant effects on functioning (Barthel Index, ${ }^{23}$ Nuremberg Alters-AlltagsSkala ${ }^{16}$ ), quality of life (EQ-5D, ${ }^{16,23}$ QOL$A D$, and Short Form-36 questionnaire ${ }^{16}$, cognition (MMSE ${ }^{16,23}$ ), caregiver mastery and burden, ${ }^{16,23}$ caregiver health-related quality of life, or caregiver EQ-5D scores. ${ }^{16}$ There were no differences in moves to care homes 
A. Meta-analysis of effects of primary care provider with case manager and specialist support compared to usual primary care upon behavioural and psychological symptoms of dementia as measured by the Neuropsychiatric Inventory $(N=2, n=414)$.

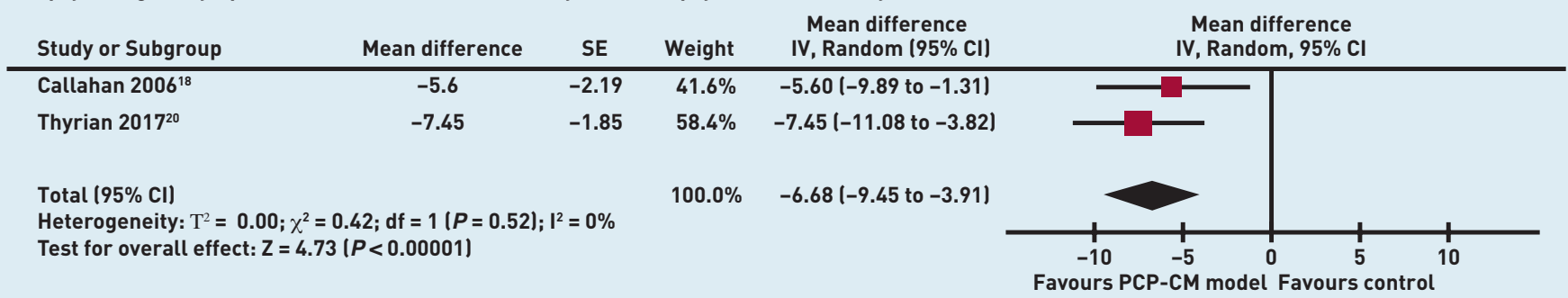

B. Meta-analysis of the effects of a PCP case management partnership model compared to usual care, using caregiver Neuropsychiatric Inventory scores (Callahan $n=153$, Mavandadi $n=75$ ) and BIZA-D (Thyrian $n=241$ )

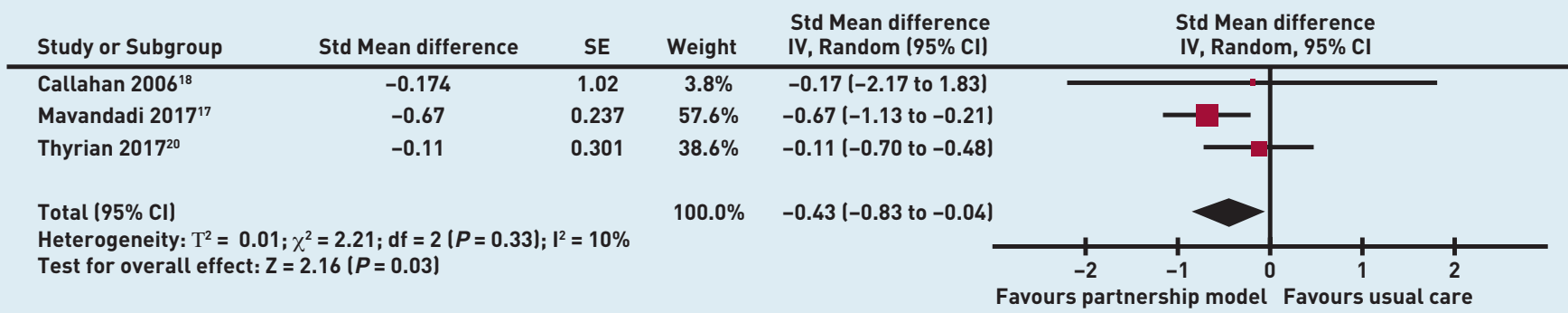

C. Meta-analysis of effects of a PCP-case management partnership model on the odds of moving to long term care over 12 months

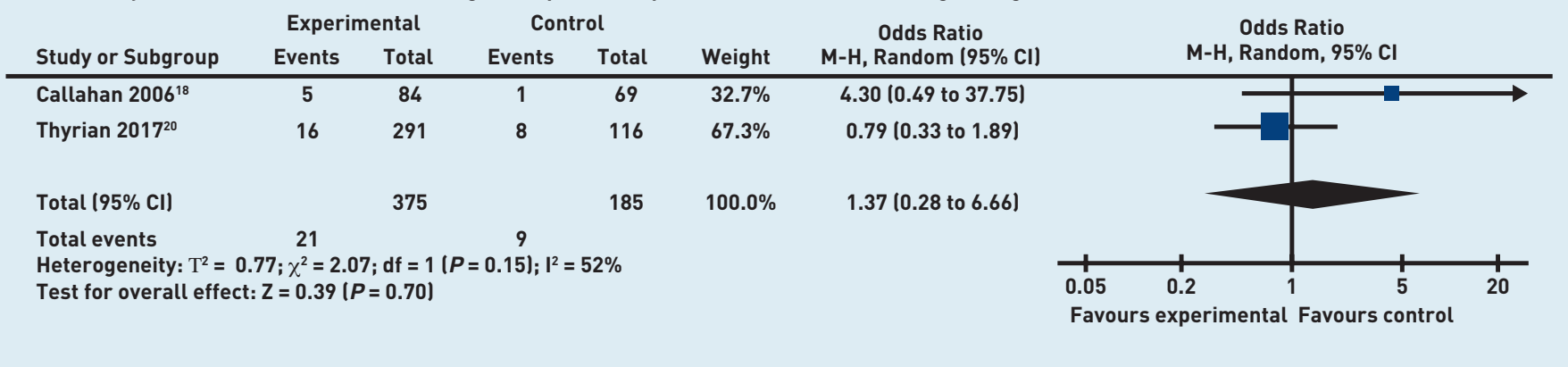

Figure 2. Meta-analysis of primary care provider-case management partnership outcomes. $I V=$ inverse variance. $M-H=$ Mantel-Haenszel. $P C P-C M=$ primary care provider-case management. Random $=$ random effects. $S E=$ standard error Std $=$ standardised. or use of other home care or healthcare services, ${ }^{16,23}$ apart from higher neurologist contacts than usual care $118.6 \%$ versus $2.8 \%, P<0.002$, not adjusted for baseline differences), ${ }^{16}$ and greater caregiver counsellor and support group uptake. ${ }^{27}$ The economic evaluation associated with the RCT was high quality, and found no differences in social care, health care, or overall costs between the three arms (Group A €82 745 [€70 470], Group B €80 361 [€68 439], and Group C €75 754 [£64 516]; $P=0.64)$, apart from higher outpatient costs than usual PCP care. $^{23}$

\section{PCP-case management partnership}

This model had sufficient studies to conduct a meta-analysis (Figure 2). There were significant effects from two RCTs ( $n=414)$ at 12 months on NPI scores (mean difference $=-6.68 ; 95 \% \mathrm{Cl}=-9.45$ to -3.91) (Figure 2A). ${ }^{18,20}$ Two further studies reporting medians or group $x$ time interaction data only found no effects over $6^{17}$ or 12 months, ${ }^{25}$ although one had a much shorter intervention period, ${ }^{17}$ and the other a small sample size. ${ }^{25}$ No studies found effects on functioning (Alzheimer Disease Cooperative Study activities of daily Living, ${ }^{18}$ Bayer Activities of Daily Living scale $\left.{ }^{20}\right)$, quality of life $\left(Q O L-A D^{20,25}\right)$, cognition (MMSE ${ }^{18,20}$ ), or depression (Cornell Scale for Depression in Dementia [CSDD] ${ }^{18}$.

Three RCTs $(n=469)$ found moderate effects on caregiver burden (NPI) at 12 months ${ }^{17,18,20}$ (standardised mean difference $=-0.43 ; 95 \% \mathrm{Cl}=-0.83$ to $-0.04 \mathrm{~J}$ (Figure 2B), although in one study these effects were not sustained at 18 months. ${ }^{18}$ For other burden measures not included in the meta-analysis, there were significant effects when measured by the Revised Memory and Behavior Problems Checklist, ${ }^{17}$ but not the Zarit Burden Interview (ZBI). ${ }^{17,25}$ Effects on caregiver self-efficacy and coping were mixed, ${ }^{17,25}$ although significant in one study with extra caregiver education content. ${ }^{17}$ No study found effects on caregiver depression (CES$D,{ }^{25} C^{2} D^{18}$, but there were lower Patient 
Health Questionnaire-9 Imean difference between groups $=-1.6 ; 95 \% \mathrm{Cl}=-3.0$ to $-0.2, \quad P=0.02,18$ months) and caregiver stress scores $(-2.2 ; 95 \% \mathrm{Cl}=-4.2$ to -0.2 , $P=0.03,12$ months). ${ }^{18}$

One RCT found higher physician and nurse visits at 12 and 18 months, ${ }^{18}$ but mean hospital days, ${ }^{18}$ hospitalisations, readmissions, and emergency department visits $^{22}$ were not different compared with usual PCP care. Evidence for effects on moving to residential care was mixed: the meta-analysis found no effects on odds of moving to residential care at 12 months (Figure 2C) lodds ratio $=1.37 ; 95 \% \mathrm{Cl}=0.28$ to 6.66, $\quad N=2, \quad n=560),{ }^{18,20}$ maintained at 18 months in one study. ${ }^{18}$ One large economic evaluation found significant reductions over 3 years (hazard ratio $=0.60$; $95 \% \mathrm{Cl}=0.59$ to $0.61, n=3249$ ), ${ }^{22}$ but this was not adjusted for baseline functioning or caregiver support. There were no costeffectiveness analyses for this model, but US claims-based analyses found medical cost savings of US $\$ 601$ ( $€ 461$ in 2013) per patient per quarter ${ }^{22}$ or US $\$ 3474$ (£2667 in 2012) per year, ${ }^{19}$ and one study concluded the programme was cost-neutral. ${ }^{22}$

\section{Integrated models}

One CCT found no differences between integrated models, usual primary care, and usual memory clinics at 12 months in quality of life (QoL-AD), caregiver burden (ZBI), emergency department attendance, or hospital admission. ${ }^{21}$ Costs did not differ between integrated models and memory clinics (Singapore [S] \$13275 versus $\mathrm{S} \$ 15308$ [€7565 versus $€ 8723$ ], $P=0.40$ ) or usual PCP care (S $\$ 13275$ versus $\mathrm{S} \$ 15766$ [€7565 versus $€ 8984$ ], $P=0.38$ ] from a societal perspective. Direct medical costs were lower at 6 months compared with usual primary care. Integrated models were considered cost-effective as they had higher QALYS at 12 months than memory clinics Imean incremental QALY $=0.07$, $95 \% \mathrm{Cl}=0.12$ to 0.018 ), leading to a cost per QALY gained of S \$29 042 ( $€ 16550$ ). ${ }^{21}$

\section{DISCUSSION}

\section{Summary}

A total of 23 papers were systematically reviewed, including 10 studies of nine interventions. There was little good-quality evidence for post-diagnostic dementia care led by or substantially involving primary care. Interventions were classified into four primary care models. The review found that PCP-led care showed effects on caregiver anxiety and depression in one study from the Netherlands, but no significant differences in depression, neuropsychiatric symptoms, quality of life, or functioning. There were lower hospital and memory clinic costs, but no overall cost savings. A PCP-led with specialist consulting support model added little value over usual PCP care for clinical, cost, and service use outcomes in two German studies of mixed quality. PCP-case management partnership models showed evidence of effects on neuropsychiatric symptoms and caregiver burden, distress, coping, and mastery, although not on functioning, quality of life, depression, or cognition across one German and four US studies of mixed quality. Evidence for the impact on moves to residential care was mixed, but claims-based economic analyses indicated that this model may be costneutral or cost-saving regarding healthcare costs. Finally, integrated memory clinics had limited-quality evidence from one Singaporean trial of improved quality of life and cost-effectiveness compared with memory clinics, but no effects on caregiver burden.

\section{Strengths and limitations}

The strengths of this review include the rigorous review process, although the authors relied on the quality of the papers' intervention reporting for inclusion decisions and classification decisions regarding primary care involvement. Therefore, it is possible that a small number of studies were excluded or misclassified. Interventions were also heterogeneous even within similar models, limiting conclusions that can be drawn about what works within models. Previous methods of classifying interventions (for example, carved out, co-managed, and integrative hubs) ${ }^{8}$ have led to few recommendations, and grouping services in this way allowed for drawing of clearer conclusions.

Additionally, many studies compared interventions with 'usual care', which is not always well defined or consistent across control services. Most trials were carried out with people with mildto-moderate dementia and few included key dementia subpopulations such as care home residents, those without a caregiver, or those with learning disabilities. Interventions were reported in varying levels of detail and the full range of components covered was difficult to determine in some studies, limiting the conclusions that can be drawn. Although quality assessment tools were used specific to study type, these tools contain items that are difficult to meet in trials that involve substantial service changes (such as participant blinding) and 
often rely on how well a study is reported. Finally, the relatively small number of studies found means the conclusions of this review may change substantially as future evidence emerges.

\section{Comparison with existing literature}

The current review focused solely on interventions involving shared decisions with a PCP and found PCP-case management partnership models offered the most promising evidence. This is similar to reviews of dementia case management alone, both within and outside of primary care, where there is evidence of meeting people's needs, improving quality of life, and reducing moves to residential care. ${ }^{7,10,28}$ The National Institute for Health and Care Excellence ${ }^{3}$ recommends a named healthcare professional to coordinate care for people with dementia in England and Wales, although the best professional for this role is still under debate. ${ }^{29}$ This review still found a lack of rigorous costeffectiveness evidence on PCP-case management partnership models; although recent studies in this review suggested reduced or neutral healthcare costs. Many outcomes were heterogeneous across studies, limiting the opportunity for metaanalysis except for PCP partnership models land even within this model studies were fairly heterogeneous), but this may improve with increasing core outcome sets.

\section{Implications for research}

This review found that specialists providing consulting advice to primary care providers had little impact on outcomes compared to usual primary care. Better evidence was found for integrated models and for incorporating specialist support into PCPcase management partnership models, but the quality of evidence was still mixed. Further rigorous evidence is needed for other models of care; for example, while evidence such as service evaluations suggest that integrated memory clinics are received positively by stakeholders, are implementable, and may reduce costs, ${ }^{30,31}$ there is currently only one non-randomised trial of this approach. Further rigorous evaluation is needed for models that show promising effects, taking country and resources into account to avoid placing an undue burden on primary care services, particularly in low- and middle-income countries.

\section{Funding}

This research was supported by funding from Alzheimer's Society (grant ref: 331). Professor Dame Louise Robinson is in receipt of a National Institute for Health Research Senior Investigator Award scheme (ref: NF-SI-0616-10054).

\section{Provenance}

Freely submitted; externally peer reviewed.

\section{Competing interests}

The authors have declared no competing interests.

\section{Acknowledgements}

The PriDem research team also includes Claire Bamford, Sube Banerjee, Doug Lewins, Lynne Corner, Raphael Wittenberg, Joy Adamson, Sally-Marie Bamford, Sue Tucker, Alistair Burns, and Alison Wheatley.

\section{Discuss this article}

Contribute and read comments about this article: bjgp.org/letters 


\section{REFERENCES}

1. Nichols E, Szoeke CEI, Vollset SE, et al. Global, regional, and national burden of Alzheimer's disease and other dementias, 1990-2016: a systematic analysis for the Global Burden of Disease Study 2016. Lancet Neurol 2019; DOI: 10.1016/ S1474-4422(18)30403-4.

2. Prince M, Wimo A, Guerchet M, et al. World Alzheimer report 2015. The global impact of dementia. An analysis of prevalence, incidence, cost and trends. London: Alzheimer's Disease International, 2015

3. Pink J, O'Brien J, Robinson L, Longson D. Dementia: assessment, management and support: summary of updated NICE guidance. BMJ 2018 . DOI: 10.1136/bmj.k2438.

4. Cheng ST. Dementia caregiver burden: a research update and critical analysis Curr Psychiatry Rep 2017; DOI: 10.1007/s11920-017-0818-2.

5. Prince M, Comas-Herrera A, Knapp M, et al. World Alzheimer report 2016. Improving healthcare for people living with dementia. Coverage, quality and costs now and in the future. London: Alzheimer's Disease International, 2016.

6. World Health Organization (WHO). Primary health care: main terminology. WHO, 2019. http://www.euro.who.int/en/health-topics/Health-systems/primaryhealth-care/main-terminology (accessed 5 May 2020).

7. Backhouse A, Ukoumunne OC, Richards DA, et al. The effectiveness of community-based coordinating interventions in dementia care: a meta-analysis and subgroup analysis of intervention components. BMC Health Serv Res 2017; DOI: 10.1186/s12913-017-2677-2.

8. Spenceley SM, Sedgwick N, Keenan J. Dementia care in the context of primary care reform: an integrative review. Aging Ment Health 2015; DOI: 10.1080/13607863.2014.920301

9. Moher D, Liberati A, Tetzlaff J, et al. Reprint--Preferred reporting items for systematic reviews and meta-analyses: the PRISMA statement. Phys Ther 2009; 89(9): 873-880.

10. Khanassov V, Vedel I. Family physician-case manager collaboration and needs of patients with dementia and their caregivers: a systematic mixed studies review. Ann Fam Med 2016; DOI: 10.1370/afm.1898.

11. Hoffmann TC, Glasziou PP, Boutron I, et al. Better reporting of interventions: template for intervention description and replication (TIDieR) checklist and guide. BMJ 2014; DOI: 10.1136/bmj.g1687.

12. Higgins JP, Altman DG, Gotzsche PC, et al. The Cochrane Collaboration's tool for assessing risk of bias in randomised trials. BMJ 2011; DOI: 10.1136/bmj. d5928.

13. Sterne JA, Hernán MA, Reeves BC, et al. ROBINS-I: a tool for assessing risk of bias in non-randomised studies of interventions. BMJ 2016; DOI: 10.1136/bmj. i4919.

14. Evers $\mathrm{S}$, Goossens $M$, de Vet $\mathrm{H}$, et al. Criteria list for assessment of methodological quality of economic evaluations: Consensus on Health Economic Criteria. Int J Technol Assess Health Care 2005; 21(2): 240-245

15. Higgins J, Green S, eds. Cochrane handbook for systematic reviews of interventions. Version 5. 1.0. The Cochrane Collaboration, 2011. https://training cochrane.org/handbook/archive/v5.1/ laccessed 5 May 2020).

16. Köhler L, Meinke-Franze C, Hein J, et al. Does an interdisciplinary network improve dementia care? Results from the IDemUck-study. Curr Alzheimer Res 2014; 11(6): 538-548.
17. Mavandadi S, Wright EM, Graydon MM, et al. A randomized pilot trial of a telephone-based collaborative care management program for caregivers of individuals with dementia. Psychol Serv 2017; DOI: 10.1037/ser0000118.

18. Callahan CM, Boustani MA, Unverzagt FW, et al. Effectiveness of collaborative care for older adults with Alzheimer disease in primary care: a randomized controlled trial. JAMA 2006; 295(18): 2148-2157.

19. French BDD, Lamantia MA, Livin LR, et al. Healthy Aging Brain Center improved care coordination and produced net savings. Health Aff 2014; DOI: 10.1377/hlthaff.2013.1221.

20. Thyrian JR, Hertel J, Wucherer D, et al. Effectiveness and safety of dementia care management in primary care: a randomized clinical trial. JAMA Psychiatry 2017; DOI: 10.1001/jamapsychiatry.2017.2124

21. Saxena N, George PP, Teo KW, et al. Evaluation of an integrated primary careled dementia shared care program in Singapore: an effectiveness and costeffectiveness study. Geriatr Gerontol Int 2018; DOI: 10.1111/ggi.13196.

22. Jennings $L A$, Laffan $A M$, Schlissel $A C$, et al. Health care utilization and cost outcomes of a comprehensive dementia care program for Medicare beneficiaries. JAMA Intern Med 2019; DOI: 10.1001/jamainternmed.2018.5579.

23. Menn P, Holle R, Kunz S, et al. Dementia care in the general practice setting: a cluster randomized trial on the effectiveness and cost impact of three management strategies. Value Health 2012; DOI: 10.1016/j.jval.2012.06.007.

24. Meeuwsen EJ, Melis RJ, Van Der Aa GC, et al. Effectiveness of dementia followup care by memory clinics or general practitioners: randomised controlled trial. BMJ 2012; DOI: 10.1136/bmj.e3086.

25. Fortinsky RH, Delaney C, Harel O, et al. Results and lessons learned from a nurse practitioner-guided dementia care intervention for primary care patients and their family caregivers. Res Gerontol Nurs 2014; DOI: 10.3928/1940492120140113-01.

26. Meeuwsen E, Melis R, van der Aa G, et al. Cost-effectiveness of one year dementia follow-up care by memory clinics or general practitioners: economic evaluation of a randomised controlled trial. PLoS One 2013; DOI: 10.1371/ journal.pone.0079797.

27. Donath C, Grässel E, Grossfeld-Schmitz M, et al. Effects of general practitioner training and family support services on the care of home-dwelling dementia patients: results of a controlled cluster-randomized study. BMC Health Serv Res 2010; DOI: 10.1186/1472-6963-10-314.

28. National Institute for Health and Care Excellence (NICE). Dementia: assessment, management and support for people living with dementia and their carers. NG97. London: NICE, 2018.

29. Backhouse A, Richards DA, McCabe R, et al. Stakeholders perspectives on the key components of community-based interventions coordinating care in dementia: a qualitative systematic review. BMC Health Serv Res 2017; DOI: 10.1186/s12913-017-2725-y.

30. Clark M, Moreland N, Greaves I, et al. Putting personalisation and integration into practice in primary care. J Integr Care 2013; DOI: 10.1108/14769011311316033.

31. Lee L, Hillier LM, Stolee $P$, et al. Enhancing dementia care: a primary care-based memory clinic. J Am Geriatr Soc 2010; DOI: 10.1111/j.1532$5415.2010 .03130 x$ 